\title{
Pensamiento crítico y cuestiones socio-científicas. Un estudio en escenarios de formación docente
}

\author{
Autora: Nidia Yaneth Torres Merchán \\ Tipo de Tesis:Tesis doctoral \\ Director: Dr. Jordi Solbes Matarredona \\ Departamento: Didáctica de les Ciencias Experimentales y Sociales \\ Universidad: Universitat de València \\ Programa: Doctorado en Investigación en Didácticas específicas (Ciencias Experimentales) \\ Fecha de presentación: 10 de junio del 2014 \\ Fecha de recepción: junio 2014 • Aceptado: julio 2014
}

Esta investigación estudia la influencia de las cuestiones socio-científicas (CSC) en las competencias de pensamiento crítico en un grupo de docentes en formación de Ciencias naturales y Educación ambiental.

Para ello se plantean las siguientes preguntas de investigación: ¿`cuáles son las concepciones que tienen los estudiantes y profesores de Ciencias sobre el pensamiento critico? ¿Qué competencias de pensamiento critico tienen los estudiantes universitarios en el ámbito de las CSC? ¿La enseñanza de las Ciencias promueve estas competencias? También ¿Cómo las CSC inciden o no en el desarrollo de competencias de pensamiento crítico en la formación profesional de estos estudiantes?

Para responder a estas preguntas se realizó una revisión sistemática de la literatura relacionada con el pensamiento crítico y el uso de las CSC. El análisis del concepto de pensamiento crítico en el campo de la Filosofía, la Pedagogía crítica y la Didáctica de las ciencias permitió argumentar que el pensamiento crítico es un conjunto de competencias que tienen las personas para estructurar una manera de pensar propia, que les permite distinguir la veracidad de los argumentos y tomar posiciones frente a las situaciones sociales para tener un papel activo en ellas. Las CSC favorecen su desarrollo en la enseñanza de las ciencias ya que permiten desarrollar las siguientes competencias: ver la ciencia como actividad social; aprender a cuestionar la información; comprender la multidimensionalidad de las ciencias (sus aspectos éticos, sociales, políticos, económicos, etc.); elaborar juicios éticos y establecer conclusiones adecuadamente sustentadas.

Para dar respuesta a estas preguntas se plantearon las siguientes hipótesis de trabajo: el pensamiento crítico es una necesidad social y de la ciencia que es poco promovido en la enseñanza de las ciencias, y el pensamiento crítico está constituido por una serie de competencias que pueden desarrollarse a través de las CSC.

A partir de lo anterior, se planeó la investigación en tres momentos: diagnóstico, intervención y evaluación. Para el diagnóstico se aplica un cuestionario sobre concepciones de pensamiento crítico y CSC a docentes en formación $(N=62)$ y en ejercicio de educación en ciencias $(N=55)$. Y otro cuestionario sobre una CSC que se utiliza como pretest: la privatización de la energía eléctrica en la región. 
La intervención se realiza con 56 estudiantes de dicha licenciatura, con el desarrollo de tres secuencias didácticas que se trabajan en grupo en el aula con las siguientes temáticas: la caracterización del pensamiento crítico (utilizando ejemplos de diversos científicos), el tratamiento del café y el uso del glifosato.

La evaluación se realiza con el análisis cualitativo y cuantitativo de las aportaciones de los grupos al trabajar las secuencias didácticas y con la comparación de los resultados del pretest que se aplica nuevamente como postest al finalizar las tres secuencias. El análisis cualitativo permite identificar una serie de categorías en cada secuencia didáctica por cada competencia. Este mismo análisis se realiza en el pretest y postest, y permite visualizar categorías emergentes dando cuenta de respuestas más elaboradas y fundamentadas.

Los resultados del cuestionario de ideas de pensamiento crítico ponen de manifiesto que los profesores señalan que falta una articulación de las asignaturas disciplinares con el pensamiento crítico. También indican que en las clases de ciencias prevalece la trasmisión de contenidos y la acumulación de conceptos y fórmulas.

El cuestionario pretest muestra que todas las competencias obtienen valores por debajo del $50 \%$, y da cuenta de las dificultades en relación con el cuestionamiento de la información, con abordar la CSC desde la multidimensionalidad y con emitir conclusiones adecuadamente sustentadas.

En relación con la intervención, el análisis de las aportaciones de los grupos permite identificar que hay una evolución en el estudio de las CSC. Se evidencia una mayor confrontación y búsqueda de fuentes de información que permite discutir acerca de la incidencia de los agrotóxicos en los ecosistemas, la importancia de informarse para elegir los productos de consumo.

El postest indica mejoras significativas en cada una de las competencias críticas establecidas en el estudio. Otros aspectos que se destacan en el postest están relacionados con respuestas más fundamentadas acerca de la producción de energía eléctrica en el país. En las cinco competencias se presentaron diferencias significativas con valores inferiores a $p<0,005$ con el pretest; esto indica el favorecimiento de competencias de pensamiento crítico a través de las CSC.

El postest permitió identificar categorías emergentes en las que se destacan la articulación de la ciencia con múltiples aspectos (sociales, éticos, políticos, ambientales); la ciencia como una herramienta que permite tomar decisiones y solucionar problemas. Se observa el carácter más social que los estudiantes dan a la ciencia.

Los resultados presentados indican la conveniencia de implementar estrategias didácticas e introducir CSC en los programas de formación docente, que van a tener repercusiones en escenarios de educación formal y no formal para promover procesos de pensamiento crítico en las clases de ciencias. 